\title{
Tracheal intubation in patients with COVID-19
}

\author{
Laura V. Duggan MD, George Mastoras MD, Gregory L. Bryson MD MSc
}

Cite as: CMAJ 2020 June 1;192:E607. doi: 10.1503/cmaj.200650; early-released May 1, 2020

\section{1}

Prepare outside the patient's room: assign team roles, check equipment and review the airway strategy

Limit the number of in-room team members depending on the patient's condition and delegate an outside-room "runner" to provide additional outside-room equipment and medications. The airway manager should be experienced enough to achieve greater than $85 \%$ first-pass success for endotracheal intubation. ${ }^{1}$ The airway strategy includes preoxygenation, positioning, endotracheal intubation and a clear plan for rescue oxygenation. ${ }^{2}$ Use a checklist to confirm in-room versus immediately available outside-room equipment and medications. Prepare all in-room materials in an airway box or go bag (Appendix 1, available at www.cmaj.ca/lookup/suppl/doi:10.1503/cmaj.200650/-/DC1). Patients with coronavirus disease 2019 (COVID-19) are "physiologically difficult." Ensure that the patient's code status is known and the crash cart is available. ${ }^{2}$

2 Don personal protective equipment (PPE) and cross-check team members ${ }^{3}$

During the severe acute respiratory syndrome epidemic, clinicians performing endotracheal intubation acquired infection at a 6 -fold greater rate than their colleagues. ${ }^{4}$ Endotracheal intubation is a high-risk, aerosol-generating medical procedure that requires high-risk PPE, including an N95 respirator or equivalent. ${ }^{3}$ Speaking may become muffled and communication more difficult once PPE is donned..$^{3}$

\section{3}

\section{Videolaryngoscopy may have benefits over direct laryngoscopy}

Videolaryngoscopy has a high first-pass success rate for experienced airway managers. A separate large screen allows the airway team to share laryngoscopy imaging and offers a greater team-to-airway distance. ${ }^{5}$

\section{4}

\section{During intubation: anticipate rapid oxygen desaturation and associated emergencies}

Use local protocols to guide intubation. Preoxygenate in a $30^{\circ}$ head-up position. Ketamine may maintain cardiovascular stability compared with other induction agents. ${ }^{2}$ Have inotropes and vasopressors in line or immediately available. Use high-dose rocuronium (1.2$1.5 \mathrm{mg} / \mathrm{kg}$ ) and ensure full neuromuscular blockade before attempting endotracheal intubation. ${ }^{2}$ Owing to aerosol generation, avoid bag-valve-mask ventilation despite desaturation. ${ }^{2,4}$ Use a styleted endotracheal tube and avoid floppy bougies to minimize contamination. After intubation, place a viral filter on the endotracheal tube and inflate the endotracheal tube cuff to ensure no leak occurs with positive-pressure ventilation. ${ }^{2}$ Waveform capnography is invaluable for confirmation of endotracheal intubation, return of spontaneous circulation in cardiac arrest and circuit disconnection. ${ }^{2}$ Should circuit disconnection occur, clamp the endotracheal tube. ${ }^{2}$ Two emergencies may occur: "cannot intubate, cannot oxygenate" and cardiac arrest. Rescue oxygenation includes supraglottic device placement and endotracheal tube cricothyrotomy using a scalpel-bougie 6.0.

\section{Removing PPE carries a high-risk of self-contamination}

$\infty$ It is difficult to detect self-contamination. ${ }^{3}$ Use a doffing checklist, read each step aloud and remove PPE as directed by a spotter. ${ }^{3}$ Interruptions during this process should be minimized.

\section{References}

1. Park L, Zeng I, Brainard A. Systematic review and meta-analysis of first-pass success rates in emergency department intubation: creating a benchmark for emergency airway care. Emerg Med Australas 2017;29:40-7.

2. Cook TM, El-Boghdadly K, McGuire B, et al. Consensus guidelines for managing the airway in patients with COVID-19. Anaesthesia 2020 Mar. 27 [Epub ahead of print]. doi: 10.1111/ anae.15054.

3. Lockhart SL, Duggan LV, Wax RS, et al. Personal protective equipment (PPE) for both anesthesiologists and other airway managers: principles and practice during the COVID-19 pandemic. Can J Anesth 2020 Apr. 23 [Epub ahead of print]. doi: 10.1007/s12630-020-01673-w.

4. Tran K, Cimon K, Severn M, et al. Aerosol generating procedures and risk of transmission of acute respiratory infections to healthcare workers: a systematic review. PLoS One 2012;7:e35797.

5. Hall D, Steel A, Heij R, et al. Videolaryngoscopy increases 'mouth-to-mouth' distance compared with direct laryngoscopy. Anaesthesia 2020 Mar. 27 [Epub ahead of print]. doi: 10.1111 /anae.15047.

Competing interests: Laura Duggan is co-founder of The Airway App (www. airwaycollaboration.org/), a smartphone app for reporting outcomes of airway management, including for COVID-19. Gregory Bryson is the Deputy Editor-in-Chief of the Canadian Journal of Anesthesia for which he receives support from the Canadian Anesthesiologists' Society. No other competing interests were declared.

This article has been peer reviewed.

Affiliations: Departments of Anesthesiology and Pain Medicine (Duggan, Bryson), and Emergency Medicine (Mastoras), University of Ottawa; Clinical Epidemiology Program (Bryson), Ottawa Hospital Research Institute, Ottawa, Ont.

Correspondence to: Laura Duggan, laduggan@toh.ca 